\title{
Disaster event: Window of opportunity to implement global disaster policies?
}

\begin{tabular}{|c|c|}
\hline $\begin{array}{l}\text { Author: } \\
\text { Siambabala B. }\end{array}$ & Manyena $a^{1,2}$ \\
\hline $\begin{array}{l}\text { Affiliations: } \\
{ }^{1} \text { Faculty of Eng } \\
\text { Environment, } \\
\text { University, Un }\end{array}$ & $\begin{array}{l}\text { Fineering and } \\
\text { Northumbria } \\
\text { ited Kingdom }\end{array}$ \\
\hline $\begin{array}{l}{ }^{2} \text { African Centr } \\
\text { Studies, North } \\
\text { University, So }\end{array}$ & $\begin{array}{l}\text { e for Disaster } \\
\text {-West } \\
\text { uth Africa }\end{array}$ \\
\hline $\begin{array}{l}\text { Corresponden } \\
\text { Siambabala M }\end{array}$ & $\begin{array}{l}\text { ce to: } \\
\text { anyena }\end{array}$ \\
\hline $\begin{array}{l}\text { Email: } \\
\text { bernard.many } \\
\text { northumbria.a }\end{array}$ & $\begin{array}{l}\text { ena@ } \\
\text { ac.uk }\end{array}$ \\
\hline $\begin{array}{l}\text { Postal address } \\
35 \text { Swinley Ga } \\
\text { Newcastle upc } \\
7 \mathrm{HX} \text {, United Ki }\end{array}$ & $\begin{array}{l}\text { s: } \\
\text { rdens, } \\
\text { on Tyne NE15 } \\
\text { ingdom }\end{array}$ \\
\hline $\begin{array}{l}\text { Dates: } \\
\text { Received: } 25 \\
\text { Accepted: } 07 \\
\text { Published: } 10\end{array}$ & $\begin{array}{l}\text { May } 2013 \\
\text { Aug. } 2013 \\
\text { Oct. } 2013\end{array}$ \\
\hline $\begin{array}{l}\text { How to cite th } \\
\text { Manyena, S.B. } \\
\text { 'Disaster even } \\
\text { opportunity to } \\
\text { global disaster } \\
\text { Jàmbá: Journa } \\
\text { Risk Studies 5( } \\
10 \text { pages. http } \\
\text { org/10.4102/j }\end{array}$ & $\begin{array}{l}\text { is article: } \\
\text { 2013, } \\
\text { t: Window of } \\
\text { implement } \\
\text { policies?', } \\
\text { / of Disaster } \\
\text { (1), Art. \#99, } \\
\text { ://dx.doi. } \\
\text { amba.v5i1.99 }\end{array}$ \\
\hline $\begin{array}{l}\text { Note: } \\
\text { Siambabala B. } \\
\text { is a post-docto } \\
\text { at the African } \\
\text { Disaster Studie } \\
\text { University, Sou }\end{array}$ & $\begin{array}{l}\text { Manyena } \\
\text { ral fellow } \\
\text { Centre for } \\
\text { es, North-West } \\
\text { th Africa. }\end{array}$ \\
\hline $\begin{array}{l}\text { Copyright: } \\
\text { (C) 2013. The A } \\
\text { Licensee: AOS } \\
\text { OpenJournals. } \\
\text { is licensed und } \\
\text { Creative Comn } \\
\text { Attribution Lic }\end{array}$ & $\begin{array}{l}\text { IS } \\
\text { IS } \\
\text { This work } \\
\text { ler the } \\
\text { nons } \\
\text { ense. }\end{array}$ \\
\hline Read online: & \\
\hline 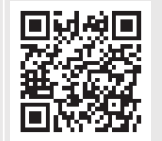 & $\begin{array}{l}\text { Scan this QR } \\
\text { code with your } \\
\text { smart phone or } \\
\text { mobile device } \\
\text { to read online. }\end{array}$ \\
\hline
\end{tabular}

Disasters have been predominantly construed as destructive events causing loss of lives, livelihoods and hard-won development. Much less attention has been paid to the constructive nature of disasters as creating potential windows of opportunities to address the overlooked and neglected aspects of disaster risk reduction. Using material from Zimbabwe, this article examines whether the humanitarian crisis, as manifested in the cholera disaster of 2008-2009, created a window of opportunity to accelerate the implementation of the Hyogo Framework for Action. The findings suggest that the humanitarian crisis did not necessarily create a window of opportunity to accelerate the implementation of the framework, owing to (1) inadequate authority and power of the agency responsible for disaster risk reduction, (2) an inadequate legal and institutional framework that outlines clear coordination, accountability mechanisms, resource mobilisation, community participation, and integration of development with regard to disaster risk reduction and (3) a lack of an integrated evidence-based approach to advocate disaster risk reduction in Zimbabwe.

\section{Introduction}

Disasters are predominantly constructed as undesirable, destructive events associated with loss of lives, livelihoods and hard-won development. Yet disasters can be constructive. A disaster can potentially be a 'wake-up call' to warn affected communities to take action concerning the overlooked or neglected aspects of disaster risk reduction (DRR). In particular, above-threshold or unprecedented disaster events such as the 2004 Indian Ocean tsunami, Hurricane Katrina in the US in 2005, the 2010 Haiti earthquake, and the 2011 Tohoku earthquake and tsunami in Japan can not only shift perception paradigms but also create 'windows of opportunity' (Birkmann et al. 2010) to enhance community resilience.

However, according to Birkmann et al. (2010) there is little empirical evidence to suggest that countries, particularly those in the developing world, that have experienced unprecedented crises have used such disaster events as 'windows of opportunity' to enhance resilience to disasters. This is an important gap which needs reflection by disaster risk scientists, particularly those involved in disciplines associated with disaster research and scholarship. But, how can we know whether these above-threshold disaster events have created 'windows of opportunities' for positive change? One of the ways is to examine whether these events have provided increased impetus to the implementation of the global disaster policy, the Hyogo Framework for Action (HFA), which was adopted in Japan in 2005.

Zimbabwe, one of the countries that ratified the HFA, experienced an unprecedented humanitarian crisis mainly due to the socio-economic decline during the 2000-2009 decade. One of the major negative impacts of the socio-economic decline was the above-threshold 2008-2009 cholera disaster, which claimed more than 4000 lives (Mason 2009; Sirajuddin et al. 2011). In this article the author questions whether the humanitarian crisis provided a 'window of opportunity' for Zimbabwe to implement the provisions of the HFA to enhance community resilience. To this end, the author turned the five actions of the HFA into the following operational questions:

- To what extent has DRR been made a national and local priority?

- To what extent has the identification, assessment and monitoring of disaster risks and earlywarning systems been enhanced?

- Has the culture of safety and resilience been enhanced using knowledge, innovation and education?

- What is the level of progress in reducing the underlying risk factors?

- To what extent has disaster preparedness improved to ensure effective response?

Using the HFA as a tool of analysis is novel and rare but can be justified in at least two ways. Firstly, the HFA is an internationally agreed DRR policy framework aimed at enhancing the resilience of nations and communities (Djalante et al. 2012). Secondly, the HFA has increasingly 
become a useful and overarching normative framework in guiding and facilitating comprehensive approaches towards DRR policies (Kishore 2011).

The sections that follow outline the HFA, Zimbabwe's hazard and vulnerability profile and the methodology. The findings of the study are presented based on the five actions of the HFA. It is concluded that there is little evidence to suggest that the humanitarian crisis, particularly the cholera disaster, provided increased impetus to implementing the provisions of the HFA in Zimbabwe.

\section{The Hyogo Framework for Action}

The 2005 World Conference on Disaster Reduction (WCDR) held in Kobe, Japan culminated in the HFA and initiated a strategic and systematic approach to building disaster resilience (United Nations International Strategy for Disaster Reduction [UNISDR] 2007:5). The WCDR emerged from a complex history of disaster and development connections, shifting from the hazard through vulnerability to resilience paradigm. In 1987, the United Nations declared the 1990s the International Decade for Natural Disaster Reduction (IDNDR) (Alexander 1991; Lechat 1990).

The IDNDR debates were dominated by scientific and technological approaches to reducing disaster risks (Hewitt 1997). In 1994, the mid-term review of the IDNDR was held in Yokohama. It was noted at the review that the IDNDR had made little impact in reducing disaster risks; in fact, there was formal recognition that disasters were 'embedded in the political structures, economic systems and social orders of the societies in which they take place' (Bankoff, Georg \& Hilhorst 2004:35). By the end of the 1990s, social dimensions of DRR started taking centre stage. There was increased recognition that disasters are a result of the combination of the exposure to a hazard, the conditions of vulnerability and insufficient resilience to reduce the negative consequences of disasters (Blaikie et al. 1994).

Thus, the HFA builds on the assumption that disasters arise when natural hazards interact with socially constructed vulnerabilities. These are conditions determined by physical, social, economic and environmental factors or processes, which increase the susceptibility of a community to the impact of hazards. Examples of socially constructed vulnerabilities include under-development, environmental degradation, climate change and preventable epidemics (UNISDR 2005:1) such as cholera and typhoid.

The HFA is also underpinned by the assumption that disasters result from a lack of resilience. Here, resilience is viewed as:

[t]he capacity of a system, community or society potentially exposed to hazards to adapt, by resisting or changing in order to reach and maintain an acceptable level of functioning and structure. This is determined by the degree to which the social system is capable of organising itself to increase this capacity for learning from past disasters for better future protection and to improve risk reduction measures. (UNISDR 2005:4)
Berkes (2007) identifies three reasons why resilience attracts increasing attention. Firstly, resilience thinking provides not only an all-hazards approach but also a comprehensive vulnerability analysis by avoiding artificial boundaries between a physical and a social emphasis. Secondly, resilience puts emphasis on the ability of a system to absorb disturbances, to learn from it and adapt, or to reorganise following the impact. This allows for multiple ways in which a response may occur across temporal and spatial scales (Berkes 2007; Berkes \& Ross 2013). Thirdly, because resilience deals with the dynamic response to hazards, it is forward looking and helps to explore policy options for dealing with uncertainty and change. Resilient systems have inbuilt redundancy by having multiple avenues for meeting needs or dealing with specific responses. Although they may be efficient, centralised and integrated systems are not necessarily resilient compared with decentralised and devolved systems, which tend to have inbuilt redundancies. Further, a resilient system has a 'feedback loop' or pattern of interacting processes, where a change in one variable, through interaction with other variables in the system, either reinforces the original process or suppresses the process (Carpenter 2011). The assumption here is that resilience provides a lens through which humanity can engage with the human-environment systems to 'live with risk' and cope with change characterised by surprises or unknowable future risks (Berkes 2007).

By focusing on vulnerability and resilience, the HFA shifts the cause of disasters from environmental determinism (acts of God and Nature) to social construction, where disasters are viewed as acts of people (Furedi 2007). From this vantage point, disasters are treated less as a pre-given ontological category and more as discursive constructions of subjectivities that are at least multidimensional, multidisciplinary and inherently full of contradictions. Examining the notions of disasters as a pre-given category can be somewhat simplistic, if not short-sighted. It can produce the assumption that disasters constitute an ontological foundation on which disaster interventions are predicated.

The UNISDR, which succeeded the IDNDR in 1999, embedded vulnerability and resilience in the HFA. The HFA rebranded disaster management, as it was then known, to DRR. DRR was defined as:

$[t]$ he concept and practice of reducing disaster risks through systematic efforts to analyse and manage the causal factors of disasters, including through reduced exposure to hazards, lessened vulnerability of people and property, wise management of land and the environment, and improved preparedness for adverse events. (UNISDR 2009:10)

The expected outcome of the HFA during the 2005-2015 period was a 'substantial reduction of disaster losses, in lives and in the social, economic and environmental assets of communities and countries'. It articulates three strategic goals. Firstly, the HFA encourages the integration of disaster prevention, mitigation, preparedness and vulnerability reduction into development programmes. Secondly, the HFA considers strong disaster institutions, mechanisms and 
capacities at all levels, in particular at the community level, to systematically contribute to building resilience to hazards. Finally, the systematic incorporation of risk reduction approaches into emergency preparedness, response and recovery programmes can also contribute to DRR. To this end, the HFA has five priority actions. Although there are no specific time-bound targets and benchmarks, each of the five actions has a series of indicators for measuring progress. Additional mechanisms for measuring progress include platforms at the global, regional and national levels. These platforms are the main multisectoral and interdisciplinary mechanisms for coordination and policy guidance on DRR for public, private and civil society participation that involve all concerned entities within a country (UNISDR 2005).

\section{The context of Zimbabwe's 2000-2009 humanitarian crisis}

Zimbabwe is located in southern Africa (Figure 1) and has a population of 12 million people.

During the first decade of this century, Zimbabwe experienced socio-economic decline, which increased its vulnerability to disasters. The contributors to the decline included strained relations with some members of the international community, reduced aid inflows, and economic and other policy implementation constraints. The decline manifested in hyper-inflationary pressures, high unemployment (70\%) and shortages of basic goods and foreign currency. This situation was exacerbated by the HIV and AIDS pandemic and loss of skilled labour to the diaspora. The socio-economic decline has weakened the support for crucial social services such as health and education. As a result, social indicators also declined dramatically. In 2011, Zimbabwe's Human Development Index was 0.376, below sub-Saharan Africa's regional average of 0.463 (United Nations Development Programme [UNDP] 2011). Similarly, the life expectancy declined from a peak of 61.5 years in 1986 to 35 years in 2006, although it rose again to 51.4 years in 2011. It is estimated

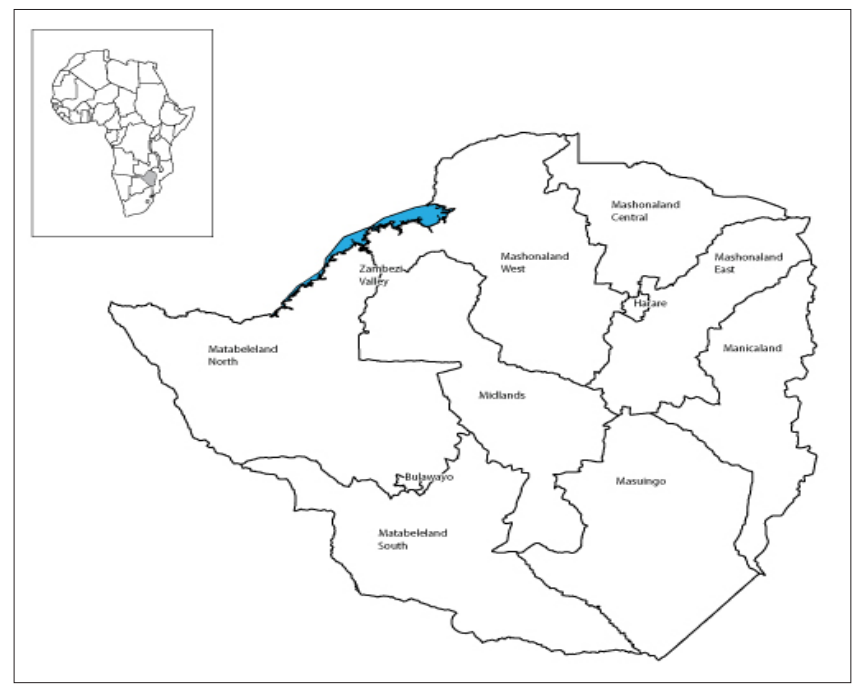

Source: Author (with assistance from Jon Swords)

FIGURE 1: Relative regional location of Zimbabwe and its provinces. that half the population survive on less than $\$ 1$ a day (UNDP 2011). In these circumstances, Zimbabwe's vulnerability to disasters has increased.

During the first decade of independence from Britain in 1980, Zimbabwe made remarkable progress towards achieving socio-economic development goals. Agriculture production from commercial and peasant farmers flourished, social indicators improved owing to improvements in social services and industry boomed. On the political front, a policy of reconciliation between Black people and White people appeared to be working. Also, the two main political parties, Zimbabwe African National Union Patriotic Front (ZANU PF) and Patriotic Front - Zimbabwe African People's Unions (PF-ZAPU), amalgamated into Zimbabwe African National Union (Patriotic Front) (ZANU [PF]).

However, by the early 1990s, Zimbabwe's economy started to decline owing to (1) the adoption of the economic structural adjustment programme, which failed to reverse the economic decline, (2) the costly but long-neglected payout to war veterans of Zimbabwe's liberation struggle, (3) corruption by ZANU (PF) elites and (4) Zimbabwe's involvement in the Democratic Republic of Congo (Kriger 2007:70). The increasing economic hardships gave rise to the Movement for Democratic Change (MDC) as an alternative to ZANU (PF). The waning support for ZANU (PF) became evident in 2000 when it lost the constitution referendum. Despite the formation of a coalition government consisting of ZANU (PF) and the MDC in 2009, the economy had virtually collapsed owing to political turmoil and infighting.

Although the coalition government was unstable because the political leaders had not adhered to the text and spirit of the government of national unity (Newsday 14 August 2011), the crisis provided opportunities to improve socio-economic and political stability, for example, through (1) a medium-term plan that set national priorities for the period 2010-2015 to foster economic growth, global competitiveness, jobs, equity, freedom and democracy and (2) the new constitution. Whilst the socio-economic decline increased vulnerability and reduced the resilience to disasters, did it provide a window of opportunity to improve DRR policies and programmes?

Zimbabwe is generally a medium- to low-disaster risk country, mostly affected by slow-onset disasters that are triggered by hydro-meteorological hazards such as droughts, cyclones and floods. Droughts, which are linked to the warm El Niño Southern Oscillation in the Pacific Ocean, tend to pose the greatest challenge to Zimbabwe's agriculturebased economy (Centre for Research on the Epidemiology of Diseases [CRED] 2012). Droughts have led to crop shortfalls, livestock decimation, water shortage and economic losses. The worst droughts were recorded in 1946-1947 and 19911992, when rainfall during the agricultural season averaged $365 \mathrm{~mm}$ and $315 \mathrm{~mm}$, respectively. In 1992, the government spent $\$ 8$ million - \$10 million a month on drought relief (Government of Zimbabwe 2008; Savage 2011). Floods have also been common in Zimbabwe over the last century and 
have broadly been associated with climate change (Eriksen, O'Brien \& Rosentrater 2007). The cyclone Eline-induced floods in the Zambezi Basin in 2000 claimed 90 lives, left more than 100000 people homeless and resulted in more than $\$ 3$ million of infrastructural damage.

Technological disasters, particularly those involving public transport, have also escalated. Although the number of accidents decreased from a peak of 60360 in 2002 to 16904 in 2008 , there has been a steady increase in accidents since 2009 (from 20553 to 31566 in 2011). Road traffic accidents are likely to continue to rise owing to the increase in vehicles, deteriorating road infrastructure and limited capacity to enforce road traffic regulations.

Nonetheless, disasters triggered by the hydro-meteorological and technological hazards that occurred during the 2000-2009 decade generally either fell within the threshold levels or could be responded to with available capacity. In relation to biological hazards, the cholera outbreak in 2008 proved to be the largest in Zimbabwe's history: over 98000 cases and more than 4000 deaths were recorded (Mason 2009; Mukandavire et al. 2011). Mason (2009) attributes the cholera outbreak to the breakdown in water supply, sanitation and hygiene facilities, breakdown in health services, a lack of diagnostic services and failure of primary health care systems. The first cholera case, clinically diagnosed as Vibrio cholera, was reported on 20 August 2008 in Chitungwiza (Mason 2009), a large urban centre on the outskirts of Harare. The cholera outbreak quickly spread to most parts of Zimbabwe. By November 2008, large outbreaks were recorded in Beitbridge on the border with South Africa. By December 2008, cholera outbreaks were reported in all 10 provinces of Zimbabwe. Mason (2009) suspects that cholera outbreaks could also have spread to neighbouring countries, namely South Africa, Zambia, Mozambique and Botswana. However, it was not until 03 December 2008 that the cholera outbreak was declared a state of emergency to allow for the mobilisation of international humanitarian aid. The World Health Organization (WHO) then set up a Cholera Command and Control Centre in Harare to coordinate international groups to distribute medication and help with the country's water treatment (Mukandavire et al. 2011).

The decentralised cholera risk reduction campaign was headed by the Department of Civil Protection (the national DRR agency) at national level, the provincial governors at provincial level, the district administrators at district level, and ward health workers at ward level (WHO 2009). In the cholera risk reduction campaign, the Department of Civil Protection was guided by the Civil Protection Act of 1989 (Government of Zimbabwe 1989). The Act provides a framework for DRR in Zimbabwe, including resource mobilisation, administration and implementation mechanisms. The Department of Civil Protection worked with the structures provided in the Civil Protection Act. At national level, the department coordinated the cholera risk reduction campaign through the National Civil Protection Committee, which also served as the National Platform. At the sub-national level, coordination was effected through planning committees for 'civil protection provinces' or 'civil protection areas', comprising technical persons from government ministries, local authorities, statutory bodies and non-governmental organisations (NGOs).

The civil protection committees meet once every month under normal circumstances. However, when a disaster occurs, meetings become more frequent until the disaster has been managed. In many ways, the cholera risk reduction campaign could have provided an impetus for the Department of Civil Protection to implement the provisions of the HFA to enhance community resilience to disasters.

\section{Methodology}

To establish whether the unprecedented cholera outbreak in Zimbabwe provided a 'window of opportunity' to implement the provisions of the HFA, both quantitative and qualitative data sources were used. Participants comprised civil protection committee members drawn from United Nations (UN) agencies, NGOs, local authorities and research institutions. A total of 161 participants, spread across the national, provincial (3), rural districts' (4) and urban councils' (3) civil protection committees completed a questionnaire. The questionnaire was adapted from the HFA indicators, with participants asked to rate the HFA progress as low, medium or high (Table 1).

Before participants completed the questionnaire, the researcher explained the HFA background, the goals and objectives, the priority actions and the indicators for each of the actions. This provided participants with basic information to help them to engage meaningfully with the questionnaire. Subsequently, on the basis of the ratings on the questionnaire, participants were asked to write notes on issues they considered to be critical for achieving the HFA's goals in Zimbabwe. The issues were grouped into themes that broadly reflected the HFA's priorities and actions. New issues that emerged from the discussion were also noted.

\section{Findings and discussion on Zimbabwe's progress in implementing the Hyogo Framework for Action}

This section presents the findings from the questionnaire and group discussions using the HFA's five priority actions and the outcome indicators.

TABLE 1: Criteria for rating the use of the indicators of the Hyogo Framework for Action in Zimbabwe.

\begin{tabular}{ll}
\hline Rating & Description \\
\hline Low & $\begin{array}{l}\text { Minor or relatively small and incomplete achievements; commitment } \\
\text { and capacity limited }\end{array}$ \\
Medium & $\begin{array}{l}\text { There is institutional commitment and capacity, but progress is not } \\
\text { substantial }\end{array}$ \\
High & $\begin{array}{l}\text { Comprehensive or substantial achievements, with commitment or } \\
\text { capacity to sustain efforts }\end{array}$ \\
\hline
\end{tabular}




\section{Hyogo Framework for Action 1: Ensure that disaster risk reduction is a national and local priority with a strong institutional basis for implementation}

The assumption of HFA1 is that strong institutional and legal frameworks, availability of resources, enhanced community participation and a functional national platform are basic elements for building resilience to disasters. HFA1 has four outcome indicators (HFA1.1-1.4) (UNISDR 2008). In relation to HFA1.1, institutional and legal policy framework and capacities should exist for DRR at all levels by 2015. This means that Zimbabwe's constitution, legal and policy frameworks, and government systems should provide the basis to develop plans and organisational arrangements for all areas of DRR in Zimbabwe. To achieve HFA1.2, the government of Zimbabwe would need to make resources available for DRR planning and implementation. Dedicated DRR resources should be included in the government's budget for the coordinating agency as well as sector ministries and departments. According to HFA1.3, community participation in DRR should be promoted by 2015 through, amongst others, networks and volunteers. Local communities will have delegated authority and resources to plan and implement DRR activities. Finally, a functional multisectoral platform should be established (HFA1.4). The national platform as a coordination mechanism should engage stakeholders from government, the United Nations, NGOs, the private sector and vulnerable groups such as women and children to discuss and share information and develop consensus on DRR.

Table 2 summarises the responses to HFA1. The majority (55\%) of participants rated the general progress towards making DRR a national and local priority as low. About 37\% and $8 \%$ rated the progress as medium and high, respectively.

More than two-thirds of the participants attributed lack of progress in achieving HFA1 to inadequate resources dedicated to DRR at national, provincial and local authority levels. Interviews with participants across the country confirmed that financial, human and material resources were inadequate. At the national level, although the Department of Civil Protection had a small budget for emergencies, there was hardly any budget allocated for emergencies at the provincial and local authority levels. When a localised disaster event occurs, sub-national structures often wait for the release of funds from the Department of Civil Protection's budget. During the 2008 cholera outbreak, the international agencies, particularly the United Nations agencies such as the United Nations Children Fund and WHO provided the bulk of the resources. In addition, there was hardly any budget for recovery.

Through observation by the researcher and interviews with civil protection committees, it was established that the structures destroyed by cyclone Eline in 2000, particularly the bridges, were yet to be rehabilitated. As a consequence of limited budgetary allocations, DRR in Zimbabwe is characterised by limited human resource capacity, inadequate materials and equipment, including transport, chemicals and vaccines for prevention of animal and crop diseases. However, participants noted that a lack of funds for DRR was not necessarily evidence of a lack of political will. In contrast, there were two major challenges, namely (1) lack of knowledge and understanding amongst decisionmakers regarding what DRR entails, including the HFA and (2) inadequate evidence to justify increasing the DRR budget to the Department of Civil Protection and across ministries. It might then be inferred that the key reasons for the lack of adequate resources can be attributed to underlying factors, primarily limited awareness and evidence-based approaches to advocate DRR amongst policymakers.

In addition to inadequate resources, about two-thirds of participants cited a lack of community participation at the local levels as a contributing factor to fully implementing HFA1. Interviews with participants highlighted that there was a disconnect between national and sub-national levels. The framework provided by the 1989 Civil Protection Act was inadequate, not only in guiding community participation but also with regard to accountability mechanisms. There were four major difficulties identified by participants: inadequate power and authority by the Department of Civil Protection, ineffective sub-national structures, response mode and centralisation. Firstly, as a department within a ministry of local government (rather than being under the stronger and politically powerful offices such as the president's or prime minister's office), the Department of Civil Protection has inadequate power and authority. This is in contrast with the study by the Commission for Africa, UNISDR and World Bank (2008), which found that countries such as Kenya, Namibia, Botswana, Lesotho, Nigeria, Seychelles, Uganda, Tanzania and Zambia had the DRR office located in the president's or prime minister's office for easier coordination across ministries and agencies. Secondly, the sub-national structures have generally been

TABLE 2: Perceptions of respondents with regard to achieving Hyogo Framework for Action 1: Making disaster risk reduction a national and local priority.

\begin{tabular}{|c|c|c|c|c|}
\hline \multirow[t]{2}{*}{ Indicator code } & \multirow[t]{2}{*}{ Description } & \multicolumn{3}{|c|}{ Rating (\%) } \\
\hline & & $\mathrm{L}$ & M & $\mathbf{H}$ \\
\hline HFA1.1 & National institutional and legal frameworks for DRR exist, with decentralised responsibilities and capacities at all levels & 44 & 46 & 10 \\
\hline HFA1.2 & Dedicated and adequate resources are available to implement DRR plans at all administrative levels & 77 & 22 & 1 \\
\hline HFA1.3 & Community participation and decentralisation are ensured through the delegation of authority and resources to local levels & 60 & 32 & 8 \\
\hline HFA1.4 & A national multisectoral platform for DRR is functioning & 34 & 50 & 16 \\
\hline Overall rating & - & 55 & 37 & 8 \\
\hline
\end{tabular}


ineffective because the Civil Protection Act does not provide for the specific designated functions, financial and material resources at both the provincial and local authority levels. Thirdly, without resources for disaster prevention and preparedness, Zimbabwe's disaster management remains in the response mode rather than focusing on vulnerability and resilience. Finally, whilst in theory DRR is decentralised in Zimbabwe, it is actually centralised, with a technical bias. The Department of Civil Protection makes decisions on even small localised disaster events. Yet since the promulgation of the Civil Protection Act in 1989, the global context for DRR has drastically advanced from the hazard paradigm, through the vulnerability paradigm, to the resilience paradigm.

Nonetheless, HFA1 indicators also recorded some progress. About half of the participants rated the progress in national institutional and legal frameworks as 'medium' (HFA1.1). The Disaster Risk Management Bill and the Disaster Risk Management Policy, whose process was initiated as early as 2005 , were being finalised by authorities almost a decade later. The Draft Disaster Risk Management framework will replace the Civil Protection Act, which will reform the Disaster Risk Management institutional framework in Zimbabwe. In these policy documents, there are three key features that make them relatively compliant with the HFA. Firstly, there is a notable shift in rhetoric from emergency preparedness and response to integrated disaster risk management that focuses on preventing and mitigating the severity of disasters, emergency preparedness, response and recovery. Secondly, there is also a decentralised framework with enhanced clarity of roles and responsibilities at national and sub-national levels. Increased emphasis has been placed on community-based DRR, not only to foster the participation of threatened communities in the evaluation of risk and ways to reduce it but also to ensure application and adaptation of local indigenous risk-coping knowledge and practices into risk reduction strategies (Annelies 2009; Kafle 2010; Maceda et al. 2009). Finally, the proposed legal frameworks outline the funding mechanisms for prevention, response and recovery. A minimum of $1 \%$ of the national and local authority budgets is set to be allocated to the Disaster Management Fund. This resonates with Norris et al. (2008), who argue that communities must develop economic resources, reduce risk and resource inequities, and attend to their areas of greatest social vulnerability to increase their resilience to disasters.

Half the participants stated that a national multisectoral National Civil Protection Committee, which also doubles as the DRR platform, was functional (HFA1.4). The national platform, which draws members from across sectors, meet bimonthly. This has become an important coordinating mechanism for mainstreaming DRR into development policies, planning and programmes. However, the minimum effectiveness of the national platform depends on resource availability and the capacity of the sub-national structures where disasters happen. This would suggest that the structural and systemic challenges may be amongst the critical elements that need to be addressed in Zimbabwe in order to build disaster resilience.

\section{Hyogo Framework for Action 2: Improving risk information and early warning}

The HFA assumes that identification, assessment and monitoring of disaster risks and enhanced early-warning systems are key elements of resilience building. If the four outcome indicators for HFA2 are achieved by 2015, Zimbabwe would have implemented:

- HFA2.1 - a robust system for risk identification and assessment for hazards and vulnerabilities, which would inform not only decision-making but also local communities about the action to take to reduce the risk

- HFA2.2 - systems for monitoring, archiving and disseminating data in an appropriate and timely manner on key hazards and vulnerabilities to allow communities to take appropriate action

- HFA2.3 - an early-warning system for all major hazards, with outreach to the communities including the assessment of risk knowledge, monitoring and warning services, dissemination and communication and response capabilities

- HFA2.4 - a system that places national and local risk assessments within the trans-boundary, regional and international contexts.

Drawing from several case studies, including the Chernobyl nuclear accident that occurred in the Ukraine (formerly part of the Russian Federation) in 1986, Linnerooth-Bayer, Loefstedt and Sjoestedt (2000) warn that trans-boundary risks can enhance historical tensions and therefore destabilise international and regional efforts for cooperation.

Table 3 shows that about half of the participants rated the progress towards achieving HFA2 as 'medium'. In contrast, $43 \%$ and $9 \%$ of the participants rated the HFA2 progress as 'low' and 'high', respectively.

TABLE 3: Perceptions of respondents with regard to achieving Hyogo Framework for Action 2: Improving risk information and early warning.

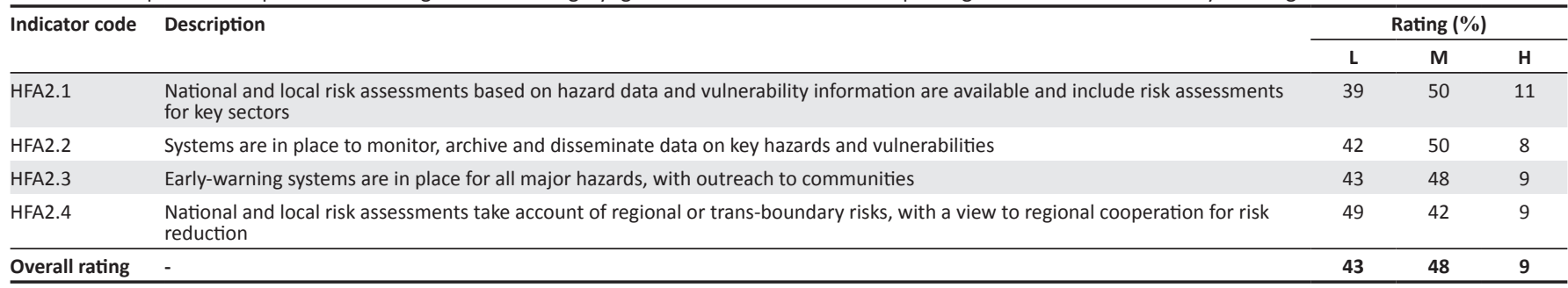

$n=161$.

The overall rating is the average of the ratings of each of the columns

HFA, Hyogo Framework for Action; H, high; L, low; M, medium. 
Of the four indicators of HFA2, three received ratings around 50\% (see HFA2.1-2.3), suggesting that hazard and vulnerability analysis and early-warning systems for major hazards were in place. This was supported by interviews with participants, who stated that hazard and vulnerability analysis and early-warning systems were in place for droughts, floods and cyclones. The Zimbabwe Vulnerability Assessment Committee (ZIMVAC), which falls under the Food and Nutrition Council, is the most prominent institutionalised approach to risk assessments. Established in 2001, ZIMVAC is a multi-agency committee, comprising government ministries, United Nations agencies and NGOs, which serves both as an early-warning system and the basis for interventions. The only difficulty is that ZIMVAC data lack clear linkages with the hazard and vulnerability data from other government agencies such as the Meteorological Services Department, the Environmental Management Agency and the Zimbabwe National Water Authority.

However, about $42 \%$ of respondents rated both HFA2.2 and HFA2.3 as low. From the author's experience and from interviews with participants, particularly at the national level, it is clear that even if Zimbabwe had relatively strong hazard and vulnerability data, such information would be difficult to access. Accessing hazard and vulnerability data involves approaching organisations individually rather than via a coordinating authority such as the Department of Civil Protection. This trend is the same at the sub-national levels. This is consistent with a study by Djalante et al. (2012) regarding the progress of implementing the HFA in Indonesia:

Despite the existence of these data, our experience was that they are difficult to locate and obtain ... the research conducted by each of these organisations are rarely disseminated in the form of research reports ... to obtain information on the types of data and their availability, one needs to approach each organisation individually. Moreover, all of these organisations are at the national level. It is even more difficult to obtain hazard and risk data at the local level. (p. 790)

With regard to HFA2.2, interviews established that there was potential to improve the coherence of the information system by integrating disparate databases into a single framework for easy access by end-users at all levels, particularly for decision-making purposes. In other words, Zimbabwe could benefit from a multihazard system by focusing on logical linkages such as shared observation systems for certain hazards and multihazard public education campaigns (International Federation of Red Cross and Red Crescent Societies [IFRC] 2009). To the extent that this may be true, early warning is a system and not a technology (IFRC 2009). Participants noted that Zimbabwe paid more attention to technical aspects of the early-warning systems than community-based early-warning systems, which would integrate indigenous knowledge systems to prompt early action to save lives and livelihoods.

In relation to trans-boundary risks, about half of the participants stated that these were amongst the major challenges (HFA2.4). The low rating for trans-boundary risk management raises questions over the Southern African Development Community's (SADC) strategies in increasing the regional cooperation in building resilience at the regional level. However, SADC has started taking some steps to address trans-boundary risks. The Zambezi River Basin Initiative is one such example, looking to build resilience amongst communities from seven countries (Angola, Botswana, Malawi, Namibia, Zambia, Zimbabwe and Mozambique) along the Zambezi River (IFRC n.d.). However, participants highlighted particular concerns for the high technological and epidemic disease risks posed at ports of entry such as Beitbridge, Chirundu and Victoria Falls. Without addressing trans-boundary risks, resilience of nations and communities to disasters cannot be guaranteed, as disasters can be region wide or can spread from one country to another.

\section{Hyogo Framework for Action 3: Use knowledge, innovation and education to build resilience}

According to HFA3, knowledge, education, research and public awareness about disasters are assumed to be amongst the key elements for building a culture of safety and community resilience. HFA3 has four indicators. The achievement of HFA3 by 2015 would mean that Zimbabwe has implemented:

- HFA3.1 - relevant information on disasters is available, accessible and understandable at all levels, including protection options for citizens in high-risk areas

- HFA3.2 - DRR is incorporated in the primary, secondary and tertiary education curricula, underpinned by an assumption that children tend to be effective agents for building resilience (Izadkhah \& Hosseini 2005)

- HFA3.3 - research systems and tools are in place for multirisk assessments and cost-benefit analysis, which are underpinned by technical, scientific and robust methodologies for assessing hazards and vulnerabilities

- HFA3.4 - a strategy for country-wide public awareness has been developed, not only to stimulate a culture of resilience but also to serve as a basis for advocacy and influencing political commitment to DRR.

As shown in Table 4, respondents placed the progress towards achieving HFA3 predominantly in the 'low' category (56\%). The 'medium' and 'high' categories scored 38\% and $6 \%$, respectively.

About two-thirds of the participants stated that there is limited systematic inclusion of DRR in the school curriculum (HFA3.2). This was rather surprising, as the Department of Civil Protection, together with the Ministry of Education's Curriculum Development Unit, United Nations agencies and NGOs, had produced educational materials, including teachers' resource books, on DRR. However, the low rating may suggest challenges in vertical and horizontal information dissemination within and between national and sub-national civil protection committees. This could also suggest that disaster education amongst policymakers, writers and publishers could generally be low, making it difficult to integrate DRR into the education curriculum.

Similarly, limited disaster research was amongst the contributing factors to little progress in achieving HFA3.3. 
TABLE 4: Perceptions of respondents with regard to achieving Hyogo Framework for Action 3: Use knowledge, innovation and education to build resilience.

\begin{tabular}{|c|c|c|c|c|}
\hline \multirow[t]{2}{*}{ Indicator code } & \multirow[t]{2}{*}{ Description } & \multicolumn{3}{|c|}{ Rating (\%) } \\
\hline & & $\mathbf{L}$ & M & $\mathbf{H}$ \\
\hline HFA3.1 & $\begin{array}{l}\text { Relevant information on disasters is available and accessible at all levels, to all stakeholders (through networks and development } \\
\text { of an information sharing system) }\end{array}$ & 53 & 37 & 10 \\
\hline HFA3.3 & Research methods and tools for multirisk assessments and cost-benefit analysis are developed and strengthened & 64 & 33 & 3 \\
\hline HFA3.4 & $\begin{array}{l}\text { Country-wide public awareness strategy exists to stimulate a culture of disaster resilience, with outreach to urban and rural } \\
\text { communities }\end{array}$ & 47 & 45 & 8 \\
\hline Overall rating & - & 56 & 38 & 6 \\
\hline
\end{tabular}

$n=161$.

The overall rating is the average of the ratings of each of the columns.

HFA, Hyogo Framework for Action; H, high; L, low; M, medium.

Disaster research was rated as low, which implies that there is a lack of research-based evidence to enable policymakers and practitioners to reflect on their practices, as well as using evidence in advocacy activities. Yet, there are several research institutions that have a remit that relate to DRR. These include the Scientific and Industrial Research and Development Centre, the Food and Nutrition Council and the University of Zimbabwe. The problem may not necessarily be related to a lack of research institutions, but rather that the individual research institutions have built some comfort zones and would feel threatened working with other institutions. For example, those working on climate change and on DRR rarely exchange data. This suggests a need for the leadership to bring disparate research groups together, particularly in strategising research focus and the dissemination of outputs.

With regard to HFA3.4, there was an almost even split between respondents who rated this indicator as 'low' and 'medium'. This could suggest that there was a slight shift towards the 'medium' category. Results from the interviews indicate that there was notable progress in raising public awareness of disaster risk, particularly through the Department of Civil Protection, the Traffic Safety Council of Zimbabwe, the Ministry of Health, the Environmental Management Agency, the Zimbabwe National Water Authority and the Zimbabwe Republic Police, which disseminated earlywarning information through electronic and print media and community and school outreach programmes. There were also efforts to translate information into local languages, including minority languages such as Kalanga, Nambia, Tonga and Venda. However, these efforts tended to be concentrated at the national level. Efforts to use social media, mobile phone technology and the internet to raise disaster awareness were still in their infancy. An evidence-based strategy for raising awareness might be needed to enhance resilience in Zimbabwe.

\section{Hyogo Framework for Action 4: Reduce the underlying risk factors}

Reducing underlying risks through environmental, social and economic policies and plans are amongst the key elements of building disaster resilient communities (HFA4). HFA4 has six output indicators. If Zimbabwe were to achieve HFA4 by 2015, it would mean that the following have been implemented:

- HFA4.1 - DRR incorporated into environmental policies and plans, including land use, natural resource management and climate change adaptation
- HFA4.2 - social development plans and policies that focus on reducing vulnerability to aspects such as food insecurity, public health, risk sharing and critical public infrastructure

- HFA4.3 - economic and sectoral policies and plans such as business continuity and recovery planning that reduce economic vulnerability

- HFA4.4 - DRR incorporated into planning and management of settlements, including enforcement of building codes

- HFA4.5 - DRR incorporated into post-disaster recovery and rehabilitation plans

- HFA4.6 - procedures for disaster risk assessments for major development projects are in place, including community involvement in all essential aspects of school and health facilities.

Progress in implementing HFA4 was generally rated as 'medium' (Table 5). However, there seemed to be a minor difference $(2 \%)$ between the two categories, suggesting a transition from the 'low' to the 'medium' category. The progress of HFA4 is attributed to the existence of environmental (HFA4.1) and social development policies (HFA4.2). In particular, the majority of participants were of the opinion that Zimbabwe's environmental impact assessment (EIA) policy of 1994 implicitly incorporated DRR measures. However, consistent with the literature, participants noted limited enforcement of the EIA policy. One of the major reasons for limited enforcement of the EIA policy appears to be that the policy is seriously fragmented owing to its 18 statutes and eight ministries having a bearing on the policy (Chinamora 1995). Further, the EIA policy was used on an ad hoc and voluntary basis as there was no coercive law to enforce it (Chinamora 1995).

Similarly, a lack of a comprehensive social policy linking DRR, recovery and development (HFA4.5) posed a major obstacle towards achieving HFA4. Social development policies that do not embed DRR may unconsciously increase vulnerability to disasters instead of reducing it. Participants were also of the opinion that DRR was not mainstreamed into recovery. This suggests that there was a disconnect between relief, rehabilitation and development, which implies that opportunities created by the disaster to 'build back better' could have been lost. However, the humanitarian situation that prevailed in Zimbabwe during the first decade of this century provided an opportunity to revisit policies or develop new ones that would incorporate DRR to some extent. Examples include the Food and Nutrition Security and the 
Social Protection policies that were being drafted at the time of this study. These policies would in many ways address the link between relief, rehabilitation and development, particularly through cash transfers and productive safety nets. In particular, these policies would not only address the widespread poverty in disaster-prone marginal areas such as Binga in the Zambezi Valley and Beitbridge in the Matabeleland South province but also improve safety for vulnerable groups such as the elderly and those suffering from HIV and AIDS.

\section{Hyogo Framework for Action 5: Strengthen disaster preparedness for effective response at all levels}

Strengthening disaster preparedness and contingency planning policies, availability of financial reserves and mechanisms for information exchange and coordination are some of the critical elements for enhancing community resilience. HFA5 has four outcome indicators. If Zimbabwe were to achieve HFA5 the following would have to be implemented:

- HFA5.1 - DRR mainstreamed into disaster preparedness and response through enhanced policy, technical and institutional capacities and mechanisms

- HFA5.2 - disaster preparedness and contingency plans in place at all administrative levels

- HFA5.3 - contingency plans that are underpinned by regular testing, drills and rehearsals to validate the plans, and financial reserves and contingency mechanisms in place to support effective response and recovery

- HFA5.4 - procedures in place to exchange relevant information during and after disaster events.

HFA5 was generally rated as low, with more than half of the participants stating that Zimbabwe had made relatively minor progress (Table 6). About $36 \%$ and $7 \%$ of the participants rated progress towards HFA5 in the 'medium' and 'high' categories, respectively. In particular, participants were of the opinion that there was a lack of technical and institutional capacity at all levels to develop, validate and implement preparedness and contingency plans. Although participants referred to a preparedness plan coordinated by the Department of Civil Protection, it was unclear whether such a plan existed; with the exception of the contingency plan developed and coordinated by United Nations Office for the Coordination of Humanitarian Affairs (UNOCHA) such a plan was difficult to obtain. Thus, the UNOCHA contingency plan served mainly the UN clusters such as agriculture, health, education, nutrition, protection, and water, sanitation and hygiene.

However, even without disaster contingency plans, regular simulation exercises were coordinated by the Department of Civil Protection to test the level of preparedness. For example, exercises were carried out to test the preparedness in the event of the wall of the Kariba Dam collapsing. Also, the Grain Marketing Board, which has been decentralised to rural districts, often maintains strategic grain reserves in anticipation of food shortages, particularly following droughts. However, drawing from the 2008 cholera outbreak, some urban and rural district councils (including the Kadoma Municipality and the Chipinge and Chiredzi rural district councils) developed some contingency plans. Whilst this might suggest a shift towards strengthening contingency plans at sub-national level, the shift is likely to be incomplete unless local communities take a leading role in developing and implementing the plans.

A lack of financial reserves or disaster funds was also a major obstacle in improving the technical and institutional capacity with regard to emergency preparedness and response. As already stated under HFA1, it is hoped that the proposed Disaster Management Fund will strengthen the capacity of government to implement DRR programmes to enhance community resilience in Zimbabwe.

\section{Conclusion}

This article has examined whether the humanitarian crisis, particularly the recent cholera disaster, provided an opportunity for Zimbabwe to accelerate the implementation of the HFA. Notwithstanding the disaster rhetoric such as DRR, vulnerability and resilience, the findings suggest that the progress in implementing the priorities of the HFA was generally rated as low. This could be attributed mainly to three overriding challenges. Firstly, there is inadequate allocation of human, material and financial resources to prevent, mitigate, prepare for, respond to and recover from disasters. Secondly, there is no legal or institutional framework for DRR that outlines clear coordination, accountability mechanisms, community participation and integration of development. Thirdly, a lack of resources or slow adoption of disaster policy frameworks indicates either limited political will or a lack of data.

The fragmented rather than integrated information management system is one of the major obstacles to an

TABLE 5: Perceptions of respondents with regard to achieving Hyogo Framework for Action 4: Reduce the underlying risk factors.

\begin{tabular}{|c|c|c|c|c|}
\hline \multirow[t]{2}{*}{ Indicator code } & \multirow[t]{2}{*}{ Description } & \multicolumn{3}{|c|}{ Rating (\%) } \\
\hline & & $\mathbf{L}$ & M & H \\
\hline HFA4.1 & $\begin{array}{l}\text { DRR is an integral objective of environment-related policies and plans, including for land use, natural resource management and } \\
\text { climate change adaptation }\end{array}$ & 37 & 51 & 12 \\
\hline HFA4.2 & Social development policies and plans are being implemented to reduce the vulnerability of populations that are most at risk & 31 & 59 & 10 \\
\hline HFA4.3 & Economic and productive sectoral policies and plans have been implemented to reduce the vulnerability of economic activities & 55 & 42 & 3 \\
\hline HFA4.4 & Planning and management of human settlements incorporate DRR elements, including enforcement of building codes & 46 & 48 & 6 \\
\hline HFA4.5 & DRR measures are integrated into post-disaster recovery and rehabilitation processes & 54 & 40 & 6 \\
\hline HFA4.6 & Procedures are in place to assess disaster risk impacts of all major development projects, especially infrastructure & 46 & 45 & 8 \\
\hline Overall rating & - & 45 & 47 & 8 \\
\hline
\end{tabular}

$n=161$.

$n=161$.
The overall rating is the average of the ratings of each of the columns.

HFA, Hyogo Framework for Action; DRR, disaster risk reduction; H, high; L, low; M, medium. 
TABLE 6: Perceptions of respondents with regard to achieving Hyogo Framework for Action 5: Strengthen disaster preparedness for effective response at all levels.

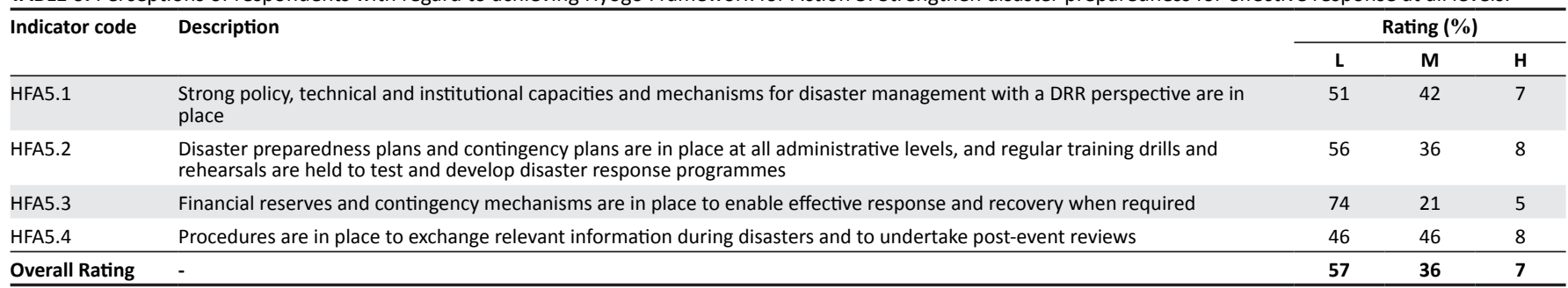

$n=161$.

The overall rating is the average of the ratings of each of the columns.

HFA, Hyogo Framework for Action; DRR, disaster risk reduction; H, high; L, low; M, medium.

evidence-based approach to advocating DRR in Zimbabwe. In a nutshell, the humanitarian crisis, particularly the cholera disaster, presented missed opportunities to use the HFA as a justification not only to address these confounding challenges but also to engender a shift from the costly response mode to the low-cost prevention mode.

\section{Acknowledgements}

I would like to thank Jon Swords for his assistance on graphics. I would also like to thank all those who participated in this study.

\section{Competing interests}

The author declares that he have no financial or personal relationship(s) that may have inappropriately influenced him in writing this article.

\section{References}

Alexander, D., 1991, 'Natural disasters: A framework for research and teaching', Disasters 15(3), 209-226. http://dx.doi.org/10.1111/j.1467-7717.1991. tb00455.x, PMid:20958724

Annelies, H., 2009, 'The social life of community-based disaster risk reduction: Origins, politics and framing', Disaster Studies Working Paper 20, Aon Benfield UCL Hazard Research Centre, London.

Bankoff, G., Georg, F. \& Hilhorst, D., 2004, Mapping vulnerability: Disasters, development and people, Earthscan, London.

Berkes, F., 2007, 'Understanding uncertainty and reducing vulnerability: Lessons from resilience thinking', Natural Hazards 41(2), 283-295. http://dx.doi.org/10.1007/ s11069-006-9036-7

Berkes, F. \& Ross, H., 2013, 'Community resilience: Toward an integrated approach', Society \& Natural Resources 26(1), 5-20. http://dx.doi.org/10.1080/08941920.2 012.736605

Birkmann, J., Buckle, P., Jaeger, J., Pelling, M., Setiadi, N., Garschagen, M. et al., 2010 'Extreme events and disasters: A window of opportunity for change? Analysis of organizational, institutional and political changes, formal and informal responses after mega-disasters', Natural Hazards 55, 637-655. http://dx.doi.org/10.1007/ s11069-008-9319-2

Blaikie, P., Wisner, B., Cannon, T. \& Davis, I., 1994, At risk: Natural hazards, people's vulnerability and disasters, Routledge, London. PMid:7798194

Carpenter, A., 2011, Resilience to violent conflict: Adaptive strategies in fragile states security management initiative, viewed 19 May 2013, from www. securitymanagementinitiative.org/index.php?option=com docman\&task=doc details\&gid $=511$ \&lang=en\&ltemid=28

Chinamora, W., 1995, 'Zimbabwe's Environmental Impact Assessment Policy of 1994 Can it achieve soundenvironmental management?', Zambezia XXII(ii), 153-163.

Commission for Africa, UNISDR and World Bank, 2008, Status of disaster risk reduction in the Sub-Saharan Africa Region, United Nations International Strategy for Disaster Reduction, Addis Ababa.

Centre for Research on the Epidemiology of Disasters (CRED), 2012, Zimbabwe: Country profile - natural disasters, Université Catholique de Louvain, Brussels.

Djalante, R., Thomalla, F., Sinapoy, M. \& Carnegie, M., 2012, 'Building resilience to natural hazards in Indonesia: Progress and challenges in implementing the Hyogo Framework for Action', Natural Hazards 62(3), 1-25.

Eriksen, S., O'Brien, K. \& Rosentrater, L., 2007, 'Climate change in Eastern and Southern Africa: Impacts, vulnerability and adaptation', GECHS Report prepared for the Norwegian Ministry of Foreign Affairs, GECHS, 2007, p. 2.

Furedi, F., 2007, 'The changing meaning of disaster', Area 39(4), 482-489. http:// dx.doi.org/10.1111/j.1475-4762.2007.00764.x
Government of Zimbabwe, 1989, The Civil Protection Act, Government Printers, Harare. Government of Zimbabwe, 2008, Disaster risk management draft policy, Zimbabwe, Department of Civil Protection, Harare.

Hewitt, K., 1997, Regions of risk: A geographical introduction to disasters, Longman, Essex.

International Federation of Red Cross and Red Crescent Societies (IFRC), n.d., Zambezi River Basin initiative, viewed 02 March 2013, from http://www.ifrc.org/docs/ appeals/09/160400-Zambezi-River-Project-LR3.pdf

International Federation of Red Cross and Red Crescent Societies (IFRC), 2009, World disaster report: Focusing on early warning and early action, International Federation of Red Cross and Red Crescent Societies, Geneva.

Izadkhah, Y. \& Hosseini, M., 2005, 'Towards resilient communities in developing countries through education of children for disaster preparedness', International Journal of Emergency Management 2(3), 138-148. http://dx.doi.org/10.1504/ IJEM.2005.007355

Kafle, S., 2010, Integrated community based risk reduction: An approach to building disaster resilient communities, viewed 19 March 2013, from http://www. preventionweb.net/files/14348_14348SheshKafleICBRR2010.pdf

Kishore, K., 2011, Literature review. mid-term review of the Hyogo Framework for Action, United Nations International Strategy for Disaster Reduction, Geneva.

Kriger, N.J., 2007, Liberation from constitutional constraints: Land reform in Zimbabwe, viewed 23 March 2013, from http://muse.jhu.edu/content/oai/journals/sais_ review/v027/27.2kriger.html

Lechat, M.F., 1990, 'The international decade for natural disaster reduction: Background and objectives', Disasters 14(1), 1-6. http://dx.doi.org/10.1111/j.1467-7717.1990. tb00967.x, PMid:20958689

Linnerooth-Bayer, J., Loefstedt, R. \& Sjoestedt, G., 2000, 'Transboundary risk management in Europe', in M.P. Cottam, D.W. Harvey, R.P. Pape \& J. Tait (eds.),
Foresight and Precaution, Proceedings of ESREL 2000, SARS and SRA-Europe Foresight and Precaution, Proceedings of ESREL 2000, SARS and SRA-Europe
Annual Conference, Rotterdam, The Netherlands, May 14-17, 2000, pp. 165-170.

Maceda, E., Gaillard, J.C., Stasiak, E., Masson, V. \& Berre, I., 2009, 'Experimental use of participatory 3-dimensional models in island community-based disaster risk management', Shima: The International Journal of Research into Island Cultures $3(1), 72-84$

Mason, P., 2009, 'Zimbabwe experiences the worst epidemic of cholera in Africa', Infection in Developing Countries 3(2), 148-151.

Mukandavire, Z., Liao, S., Wang, J., Gaff, H., Smith, D.L. \& Morris, J.G., 2011, 'Estimating the reproductive numbers for the 2008-2009 cholera outbreaks in Zimbabwe',
Proceedings of the National Academy of Sciences 108, 8767-8772. http://dx.doi. Proceedings of the National Academy of Sciences 108, 8767-8772. http://
org/10.1073/pnas.1019712108, PMid:21518855, PMCid:PMC3102413

Norris, F., Stevens, S., Pfefferbaum, B., Wyche, K. \& Pfefferbaum, R., 2008, 'Community resilience as a metaphor, theory, set of capacities, and strategy for disaste readiness', American Journal of Community Psychology 41(1), 127-150. http:// dx.doi.org/10.1007/s10464-007-9156-6, PMid:18157631

Savage, D.A., 2011, 'The unthinkable: Who survives when disaster strikes - and why', Disasters 35, 284-286. http://dx.doi.org/10.1111/j.1467-7717.2010.01225.x

Sirajuddin, A., Bardhan, P.K., Anwarul, I., Mazumder, R.N., Khan, A.I., Islam, M.S. et al., 2011, 'The 2008 cholera epidemic in Zimbabwe: Experience of the ICDDRB team in the field', Journal of Health, Population and Nutrition 29, 541-546.

United Nations Development Programme (UNDP), 2011, Human Development Report 2011 - Sustainability and equity: A better future for all, United Nations Development Programme/Palgrave Macmillan, New York.

United Nations International Strategy for Disaster Reduction (UNISDR), 2005, Building the resilience of nations and communities to disasters: Hyogo Framework for the resilience of nations and communities to disasters: Hyogo Framework for Action 2005

United Nations International Strategy for Disaster Reduction (UNISDR), 2007, Building disaster resilient communities: Good practices and lessons learned, United Nations International Strategy for Disaster Reduction, Geneva.

United Nations International Strategy for Disaster Reduction (UNISDR), 2008, Indicators of progress: Guidance on measuring the reduction of disaster risks and the implementation of the Hyogo Framework for Action, United Nations International Strategy for Disaster Reduction, Geneva.

United Nations International Strategy for Disaster Reduction (UNISDR), 2009, Terminology on disaster risk reduction, United Nations International Strategy for Disaster Reduction, Geneva.

'Viewpoint: Zimbabwe: A failed State that functions?', Newsday, 14 August, 2011

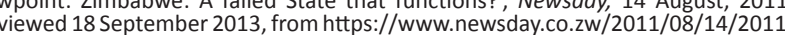
08-14-viewpoint-is-zimbabwe-a-failed-state-that-functions/

World Health Organization (WHO), 2009, Zimbabwe Health Cluster Bulletin No 5. 12 January 2009, viewed 19 May 2013, from http://www.who.int/hac/crises/zmb/ sitreps/health_cluster_bulletin_12jan2009/en/index.html 